\title{
Bioassay Vessel Rupture Analysis
}

\author{
Philip R. Vormelker
}

Submitted: 11 May 2009/Published online: 3 June 2009

(C) ASM International 2009

\begin{abstract}
Two high-pressure bioassay vessels failed at the Savannah River Site during separate events using a standard procedure for microwave heating of biosamples. Improper installation of the thermal shield in the first vessel caused the rupture during microwave heating. The second vessel rupture is attributed to over pressurization during testing. The vessel rupture appeared to initiate in the mold parting line, the thinnest cross-section of the octagonal vessel. No material flaws were found in the vessel that would impair structural performance during typical usage. Limits to thermal cycling have been suggested to avoid premature vessel rupture due to fatigue.
\end{abstract}

Keywords Bioassay · Polymer - Overpressure ·

Temperature $\cdot$ Bulging $\cdot$ Rupture

\section{Introduction}

Routine bioassay sample testing was performed at the Savannah River Site for personnel evaluation. Two polymeric bioassay vessels ruptured at recorded temperatures from 220 to $230{ }^{\circ} \mathrm{C}$ and recorded pressures ranging from 325 to $550 \mathrm{psig}(2.2-3.8 \mathrm{MPa})$. The door of a microwave oven door glass blew out during an earlier rupture (Fig. 1) that was not included in this analysis. All three ruptures occurred during a 3-month testing period.

During normal test procedures, a small bioassay sample, a gel-type cation resin, and concentrated nitric acid are

P. R. Vormelker $(\bowtie)$

Savannah River National Laboratory, PO Box 616,

Building 773-41A, Aiken, SC 29808, USA

e-mail: phil.vormelker@srnl.doe.gov placed into a polytetrafluoroethylene (PTFE) inner vessel and a thermoplastic polyetherimide (PEI) outer vessel. The vessel is then heated to a maximum of $220{ }^{\circ} \mathrm{C}$ for a minimum of $35 \mathrm{~min}$. The maximum pressure is pre-set to be controlled to less than $550 \mathrm{psig}(3.5 \mathrm{MPa})$. The sample vessels are hot after the test and are allowed to cool down prior to handling. Gel-type resin is used for selective separation of metals, specifically plutonium and americium, from the bioassay sample.

The inner vessel is designed for temperatures up to $250{ }^{\circ} \mathrm{C}$ (PTFE softening temperature) and for pressures up to 625 psig $(4.3 \mathrm{MPa})$. Burst tests by the manufacturer revealed vessel rupture at $1500-1700 \mathrm{psig}(10.3-11.7 \mathrm{MPa})$ at $23{ }^{\circ} \mathrm{C}$ and approximately $1200 \mathrm{psig}(8.3 \mathrm{MPa})$ at $220^{\circ} \mathrm{C}$.

For bioassay testing, a pressure relief disk is normally mounted on the top of each vessel. The disk is shown by manufacturer's testing to release the vessel pressure at 720 psig (5 MPa). The pressure relief disk did not release during the two vessel ruptures described in this paper.

During normal testing, ten vessels are inserted in the microwave carousel and one of these vessels is connected to a pressure sensor for microwave wattage control. Power is increased incrementally until reaching the maximum pressure per test procedure. The pressure in the inner container increases when the microwave is in operation because of decomposition of the organics and vaporization of water in the bioassay samples. The electronic pressure protection and control system shuts off power if the vessel pressure reaches $625 \mathrm{psig}(4.3 \mathrm{MPa})$. The control system also monitors temperature in the same vessel.

The vessel design (Fig. 2) is such that the bioassay sample is placed in the inner vessel which is then placed in the outer vessel. The cap to inner vessel is then fitted on top of the inner vessel. The screw on cap for the outer vessel is then placed over the inner vessel cap and tightened. The 


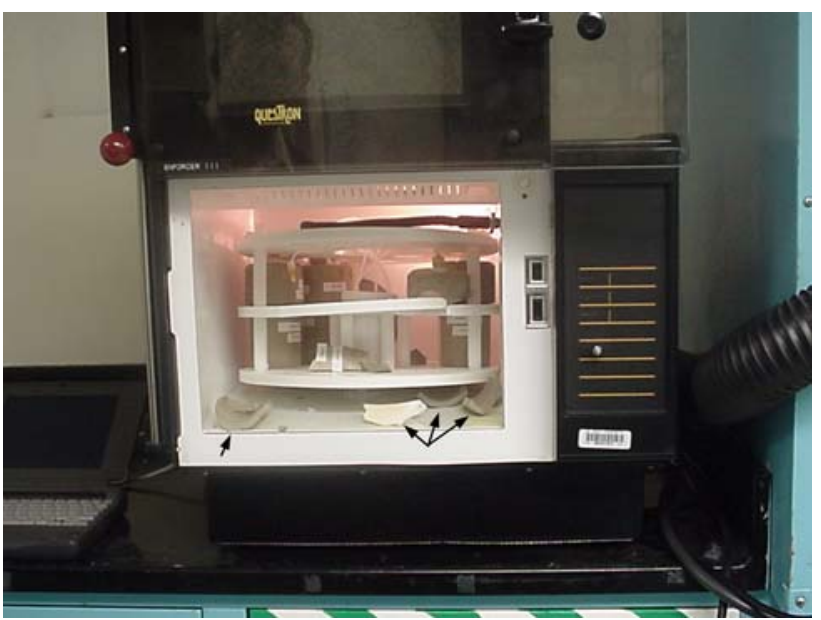

Fig. 1 Interior of microwave after vessel rupture. Parts of the failed vessel remained in the microwave after rupture (shown by arrows) and the vessel carousel was also damaged

tightening process seals the inner vessel cap to the vessel body creating a pressure tight container. The inner vessel slip on cap holds the pressure relief device. The pressure relief device includes a threaded nozzle with an internal hole and a pressure relief disk. The threaded nozzle is made of PTFE polymer while the relief disk is made of PFA (perfluoroalkoxy, a variation of PTFE). The inner vessel contains the biomaterial and is machined from a modified PTFE polymer, Dyneon TFM $^{\text {TM }}$ PTFE 1700 (DTFM). ${ }^{1}$ This vessel is inserted into the outer vessel which is made of injection-molded polyetherimide Ultem ${ }^{\mathrm{TM}} 2300 .^{2}$ The PTFE and PFA polymers are nearly transparent to microwave energy due to their low dissipation factors (ratio of the material's power absorption (heat) to the power transmitted through it) [1-3]. Thus, heating of the inner and outer vessels is due to the heating of the contained bioassay samples.

The inner vessel reaches approximately $220{ }^{\circ} \mathrm{C}$ during the microwave heating process. The outer vessel remains at a lower temperature because of the limited thermal conductivity of polymers.

\section{Results and Discussion}

\section{First Rupture}

Figure 3 shows that the bottom of the outer vessel fractured with no visible cracking in the upper part of the vessel. The

\footnotetext{
1 Trademark of Dyneon LLC, Oakdale, MN, USA.

2 Trademark of General Electric, Schenectady, NY, USA.
}

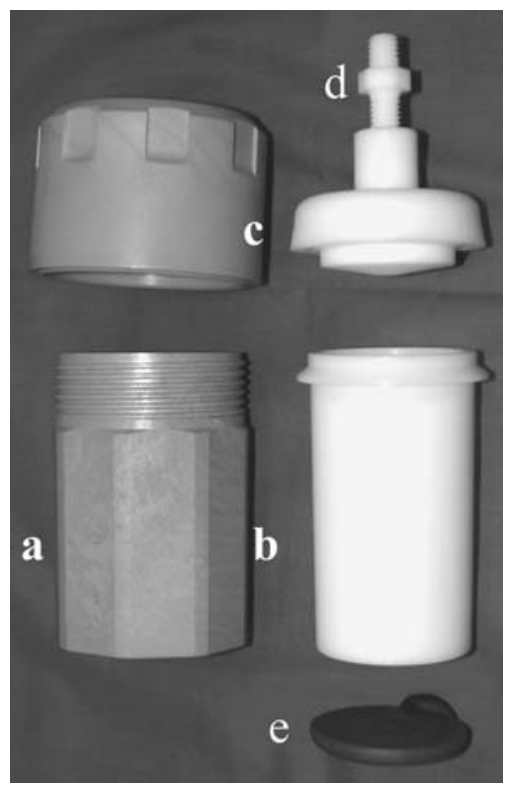

Fig. 2 Components of outer (a) and inner (b) vessels and caps. This cap (c) includes threaded pressure relief nozzle (d). Thermal shield (e) is inserted in bottom of outer vessel

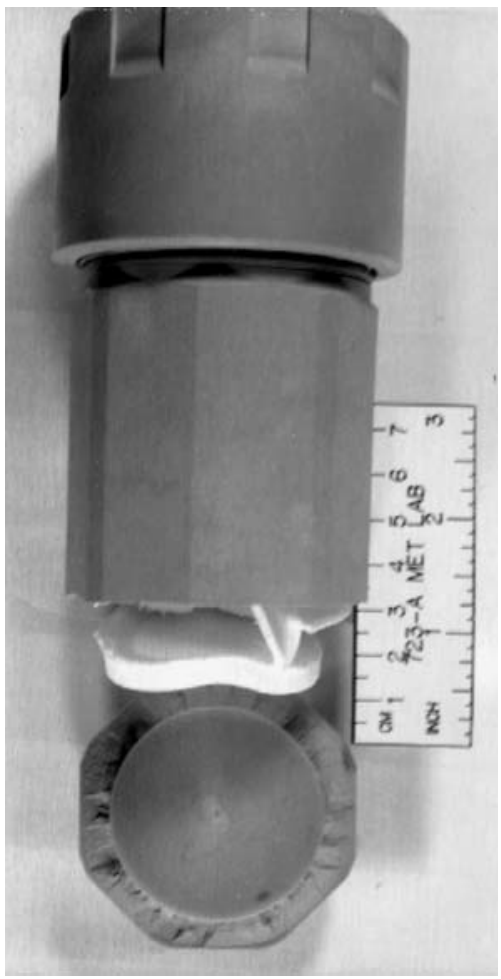

Fig. 3 The first vessel rupture (No. 1) reveals full bottom head separation. This rupture mode differed considerably from the No. 2 rupture shown in Fig. 6

cap did not fail. In Fig. 4, the thermal shield is inserted into the bottom piece of the vessel in the upright position. The top surface of the shield is above the fractured surface. 

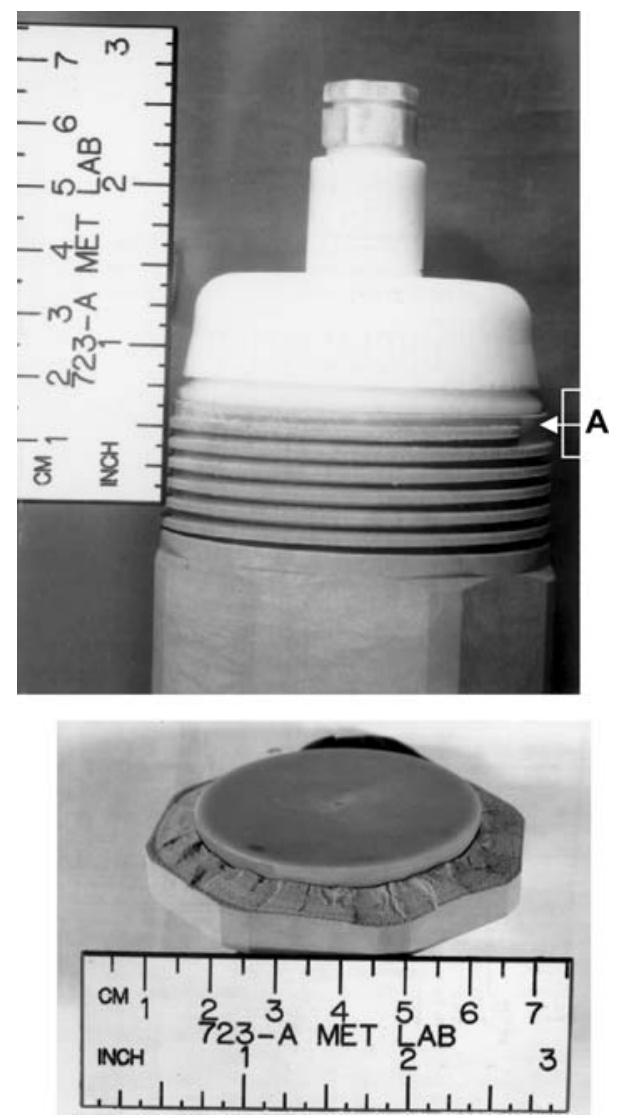

Fig. 4 Inner vessel shown inserted into outer vessel with correctly placed thermal shield (lower photo). No gap is visible at A

However, where the shield is shown upside down (Fig. 5), the position of the fractured surface is near the bottom edge of the shield. This is consistent with the manufacturer's position that the vessels will fail at lower than anticipated pressures if the thermal shield is inverted. When the thermal shield is installed correctly, the installed inner vessel and cap will look like Fig. 4. When installed incorrectly, there is a slight gap, approximately $1 / 16$ in. $(8 \mathrm{~mm})$, as shown in Fig. 5. The tightening of the outer vessel cap when the thermal shield is upside down would therefore impose additional compressive stresses on the inner vessel and an axial tensile stress on the outer vessel. This axial stress is additive to the stresses induced by pressurization of the inner canister and will lower the rupture pressure of the outer container.

Differential thermal expansions between the thermal shield and the outer vessel and between the inner and outer vessels may also contribute to the failure. The differential thermal expansion between the hot inner vessel and the colder outer vessel will increase the compressive stresses on the inner vessel and also increase the axial tensile stress acting on the wall of the outer vessel. Thus, the
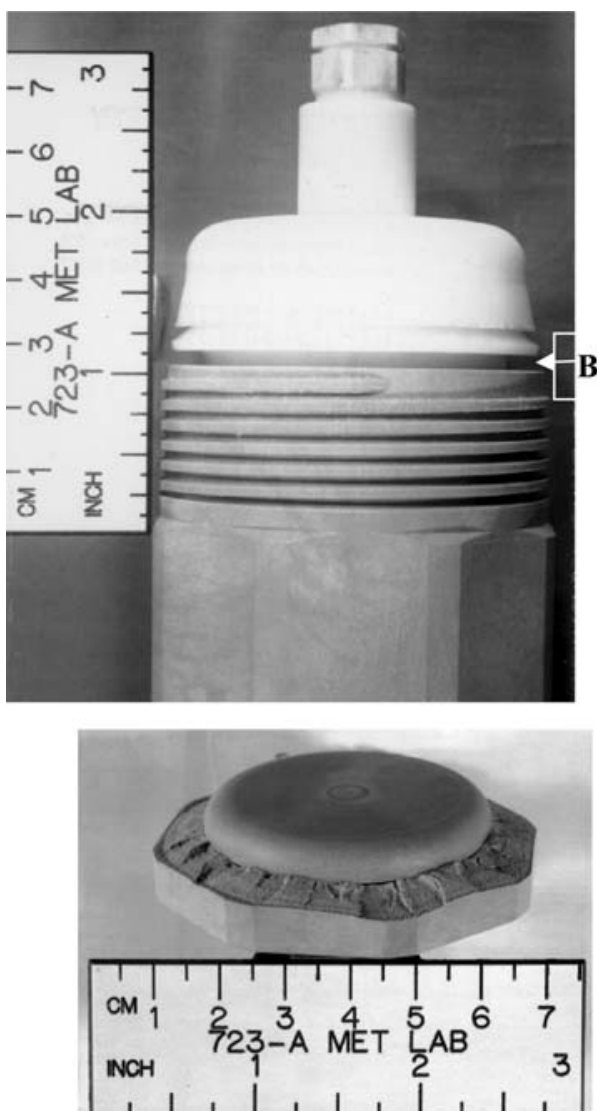

Fig. 5 Inner vessel shown inserted into outer vessel with inverted thermal shield as shown in lower photo. Note $\sim 1 / 16$ in. gap at $B$ between inner vessel and top of outer vessel

combination of stresses induced by cap tightening, internal pressure and differential thermal expansion all act to place the outer vessel in axial tension. The tensile stress on the outer vessel wall increases as the temperature and pressure inside the inner vessel increase.

It is unlikely that circumferential pressure from thermal expansion of the thermal shield plays a role in the rupture. However, the combination of axial expansion of thermal shield and inner vessel pressure, coupled with the tightening induced stresses, could be sufficient to cause rupture at the bottom of the outer vessel. When the thermal shield is inverted, the tightening stresses could easily be higher than those induced with a properly placed thermal shield. This scenario is consistent with the manufacture's position that an inverted thermal shield could lower the rupture pressure of the container system.

The fracture of the outer vessel would relieve the compressive axial stresses acting on the inner vessel wall and suddenly require the now non-supported, inner vessel wall to carry the tensile stresses induced by the internal pressure. The sudden change in stress state caused the inner vessel to fracture, as shown in Fig. 3. 


\section{Second Rupture}

Initial observation of this rupture revealed that the outer vessel (PEI) cracked into multiple pieces while the inner vessel also showed multiple cracks but did not fragment nearly as extensively as the outer vessel (Fig. 6). Sides of the inner vessel (PTFE) appeared to have blown out with the initial rupture occurring near the bottom (Fig. 7 and 8). A bulge is visible on the side of the PTFE vessel, just above a "notch" in the fracture path (Fig. 8). A similar "notch" also appears in the outer vessel, just below the notch in the inner vessel (Fig. 8). The bulge is shown at higher magnification in Fig. 8B. No defect in the PTFE is visible at this location but this is considered to be the initial rupture site of the PTFE. It appears that pressure in the PTFE vessel caused localized expansion and ballooning of

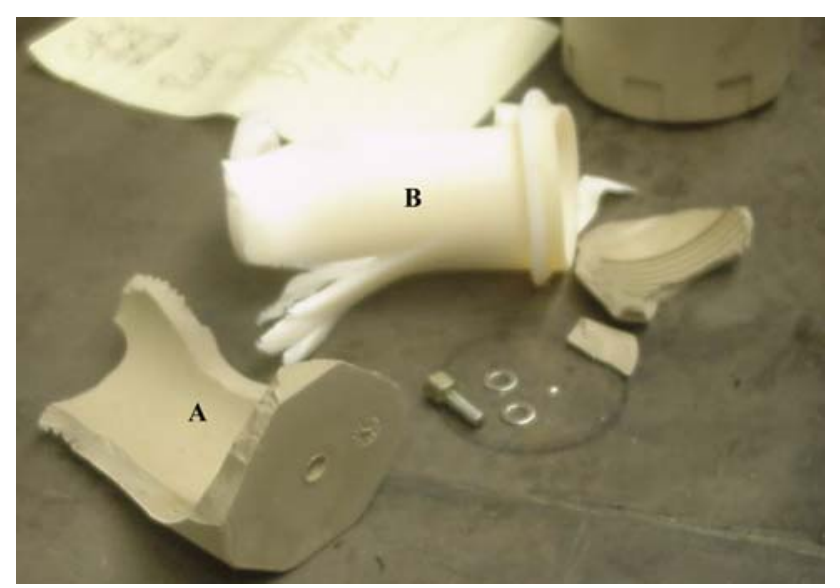

Fig. 6 Parts of the second failed vessel that were ejected from the microwave oven. The outer vessel is identified by A with the inner vessel by B. The single screw and washers are not part of this vessel. The round component beneath the washers is the thermal shield the inner vessel. The ballooned portion of the inner vessel pressed against the wall of the outer vessel, localizing the stresses in that region. When the localized stresses exceeded to fracture strength of the outer vessel, the outer vessel ruptured. The inner vessel was then free to expand and crack and fracture of the inner vessel initiated at the bulge. The inner vessel fracture was accompanied by both

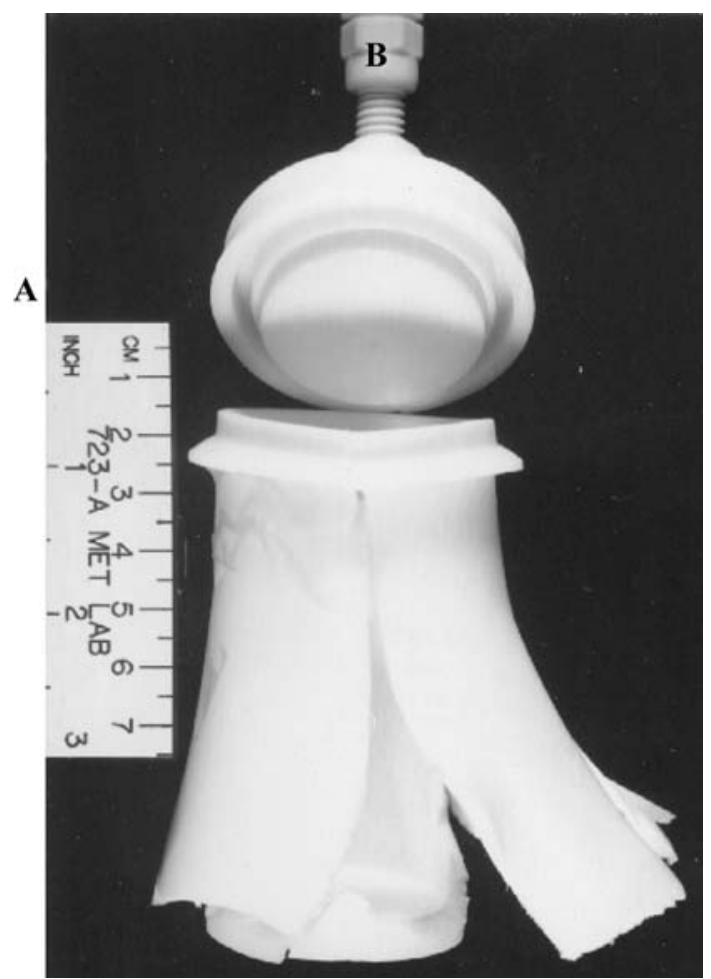

Fig. 7 The initiation of rupture in the inner PTFE vessel (second vessel rupture) appears to occur either circumferentially at the bottom, in a vertical direction, or both
Fig. 8 Inner PTFE vessel of Fig. 7 is shown positioned within outer vessel. Note matching fracture peaks in inner and outer vessels (A). A bulge in the PTFE is visible at B with an enlarged view on right which is most likely the initial site of the PTFE vessel rupture after rupture of the outer vessel
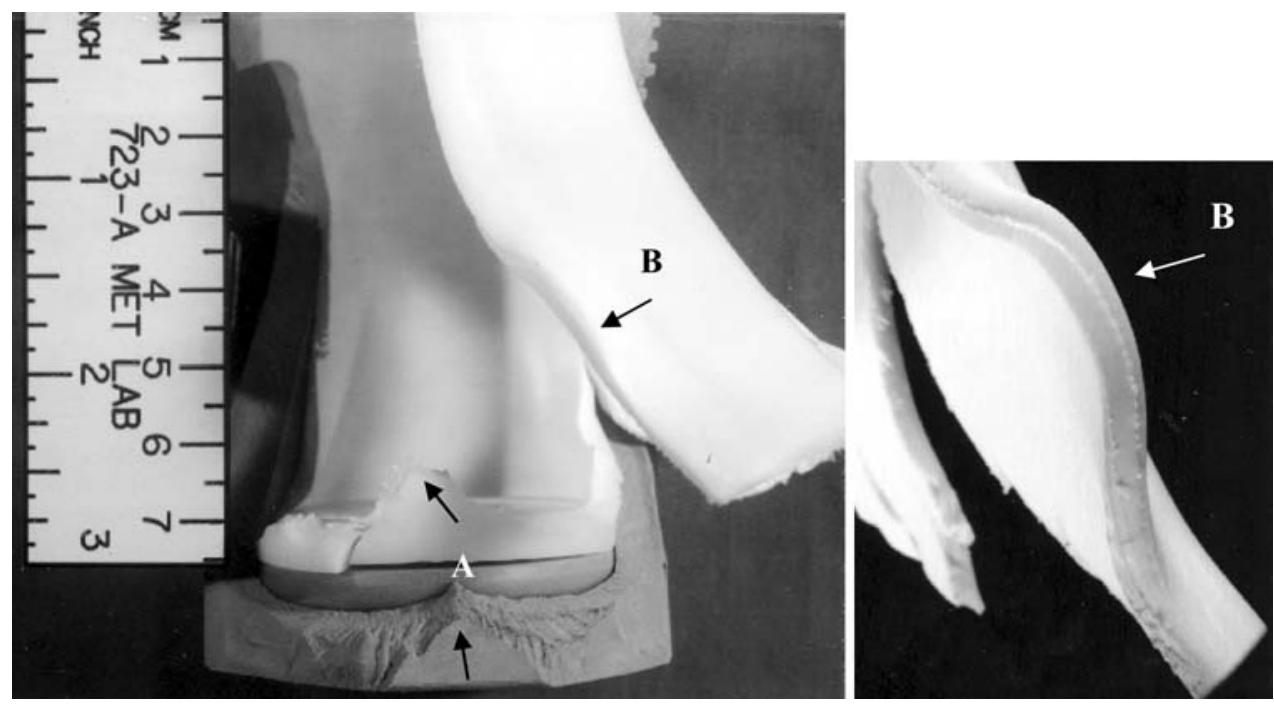


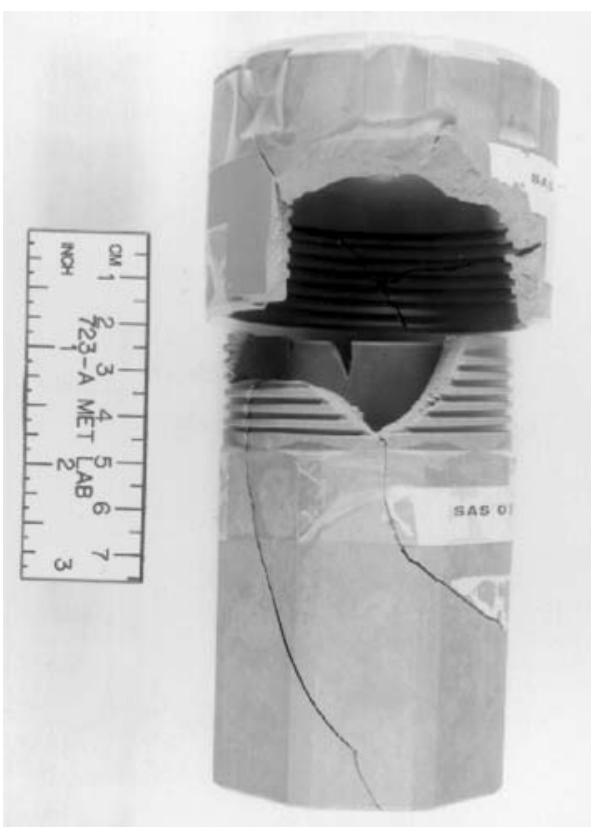

Fig. 9 The outer vessel from the second vessel rupture showing components taped together. Note that all cracks propagated along a curved path on the bottom part of the shell in this photo

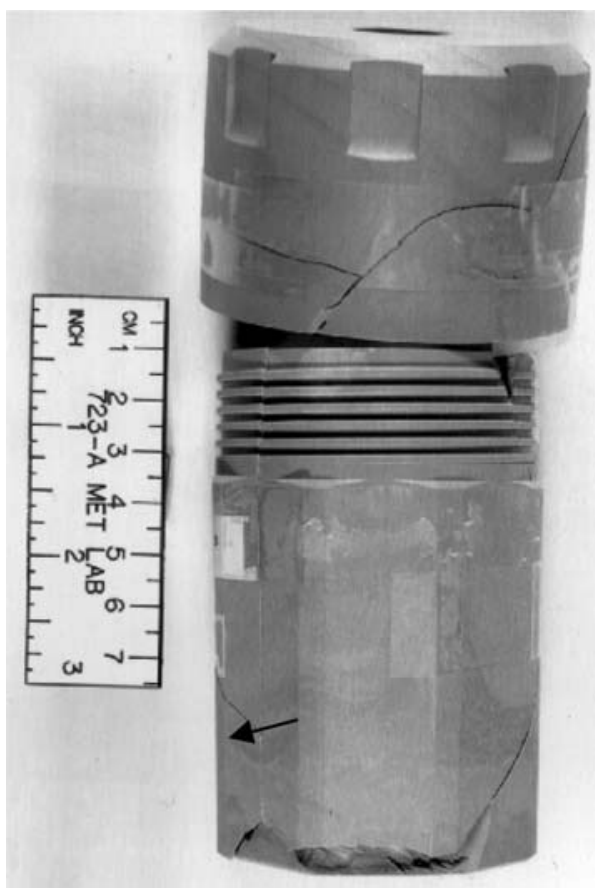

Fig. 10 Opposite side of the failed outer vessel from Fig. 9 with components taped together. In this case, a crack is barely visible along the mold parting line at arrows

circumferential cracking at the bottom and axial cracking through the bulge and at other locations.

The lack of macroscopic ductility in the PEI outer vessel is apparent when the failed outer vessel is taped

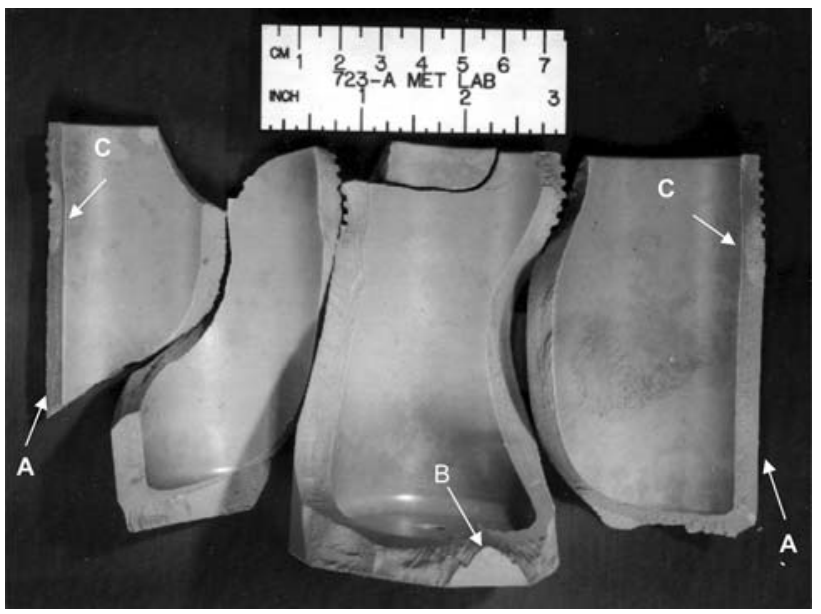

Fig. 11 Second vessel rupture. Failed outer shell components lined up side by side to show vessel fracture surfaces. The mold parting line is located at arrows marked A. The crack appears to initiate either near B or slightly above it where the bulge in the PTFE vessel occurred. At $\mathrm{C}$ the fracture surface appears lighter, possibly due to a decrease in crack growth rate because of the constraint imposed by the cap that was present over the threaded portion of the container

together (Fig. 9). The multiple cracks in the outer vessel and the associated cracking of the screwed on lid show that the initial fracture was accompanied by the rapid release of stored strain energy. Some of the stored strain energy was released by the formation of new fracture surfaces in the PEI outer vessel. The crack pattern (Fig. 10 and 11) suggests the mold parting line was a region that was very susceptible to fracture. An injection molded part usually displays two lines, $180^{\circ}$ apart where the mold separates, similar to a clamshell. When the components of Fig. 9 and 10 are laid side by side, fracture at the mold parting line is clearly visible (Fig. 11). However, other crack paths were also active during the fracture process. It should be emphasized that the fracture of both the inner and outer vessels was accompanied by large-scale strain energy release and multiple fractures.

Based upon the above discussion, the outer vessel failed first due to localized stress concentrations developed because of the expansion and bulging of the inner vessel. The absence of strain hardening in the PTFE material assures that once bulging initiates, deformation will continue in the bulged region. Assuming that the internal pressure in the inner container is uniform, bulging will initiate in the weakest and probably the thinnest portion of the container wall. As the bulge presses against the outer vessel, the stress in the outer vessel increased and was highest at the region of contact between the bulge and the outer vessel wall.

The stresses in the outer vessel wall could have been higher than expected if there was moisture in the annular space between the two vessels. The addition of pressure 


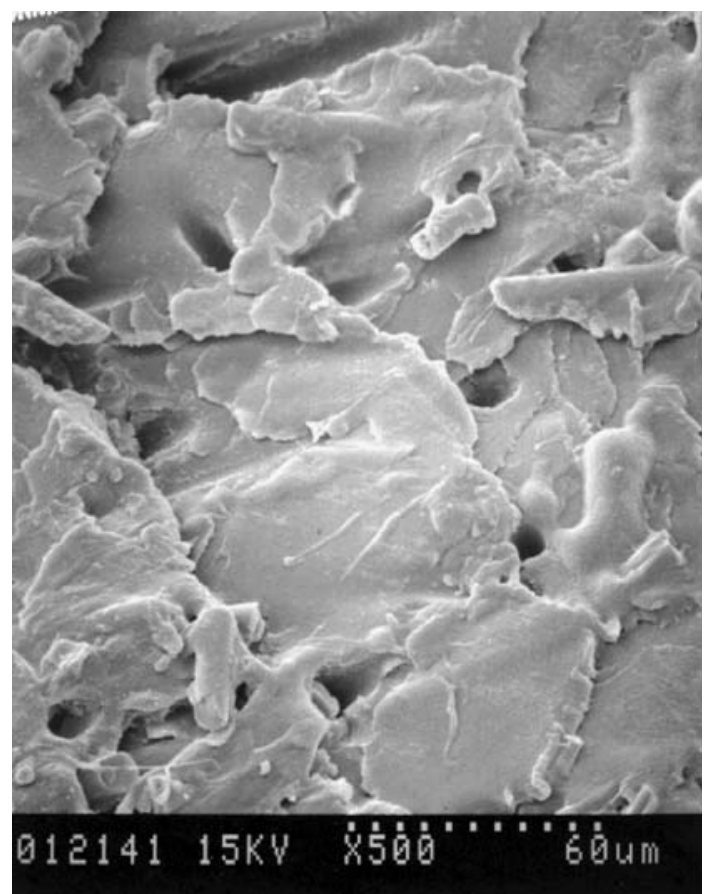

Fig. 12 Fracture surface below light color $\mathrm{C}$ location in Fig. 13. The fracture surface appears very brittle and is consistent with rapid crack growth rates. Round holes are prior fiber locations. Note that the magnification is only $500 \times$ compared with $800 \times$ in Fig. 13

from the conversion of absorbed moisture to steam in the annular space would have increased the strain energy in the vessel wall and may cause rupture at lower than expected inner vessel pressures. However, the rupture appears to have initiated near the bulge as shown in Fig. 8 and bulging would have been inhibited if pressure developed in the annular space.

SEM evaluation of the fracture surfaces showed two different types of fractures. One (Fig. 12) shows a flat, brittle fracture typical of rapid crack growth in fiber reinforced plastics. This fracture topography was found in the grey colored areas lying below the light color area (C) of Fig. 11. Another type of fracture topography was observed in light color area at $\mathrm{C}$. This topography was typical of slow crack growth in ductile, fiber reinforced plastics (Fig. 13), and shows both fiber pullout and plastic deformation of the polymer matrix. When compared to the fracture surface of a deliberately failed vessel, the induced fracture surface (Fig. 14), the surface of Fig. 13 appears very similar but the induced fracture showed less evidence of plastic deformation.

\section{Pressure Relief Device Testing}

A common element in these ruptures is that the pressure relief device did not release. The manufacturer tests of the pressure relief device showed that the release pressure was

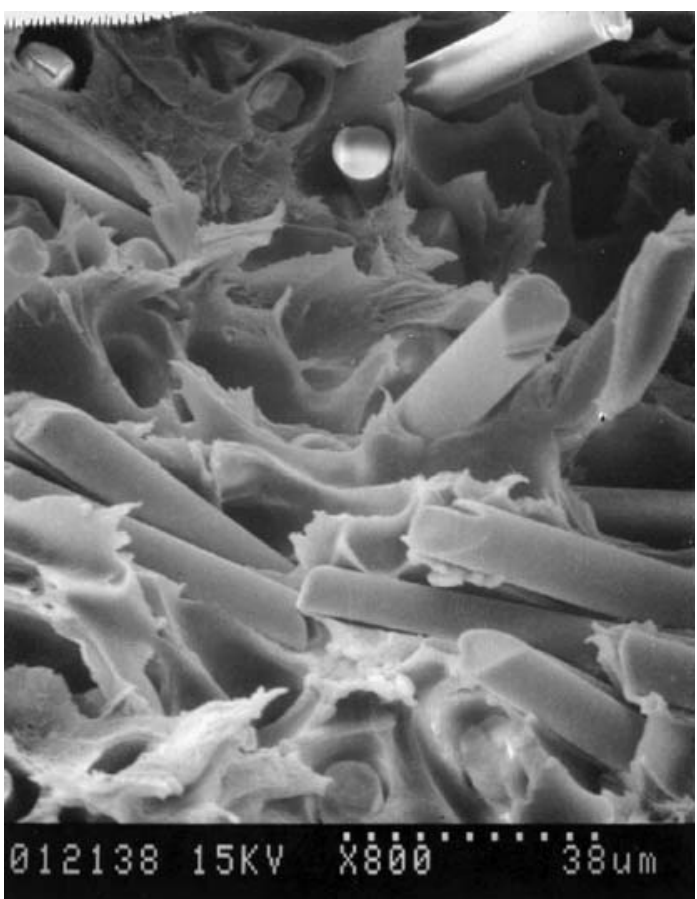

Fig. 13 Fracture surface at $\mathrm{C}$ location (light color) in Fig. 11 showing glass fibers sticking out of a torn, ductile surface. This topography suggests low crack growth rates

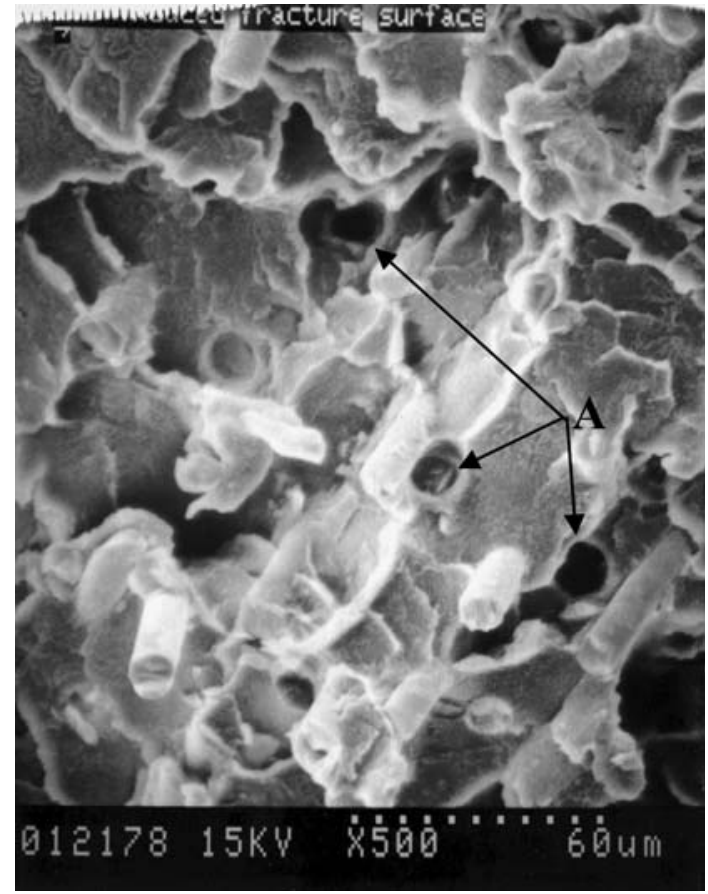

Fig. 14 Fracture surface of induced rupture of new vessel showing relatively flat but ductile surface with fibers and a few holes (A) where fibers were pulled out. This fracture surface suggests crack growth rates intermediate between those associated with Fig. 12 and 13 


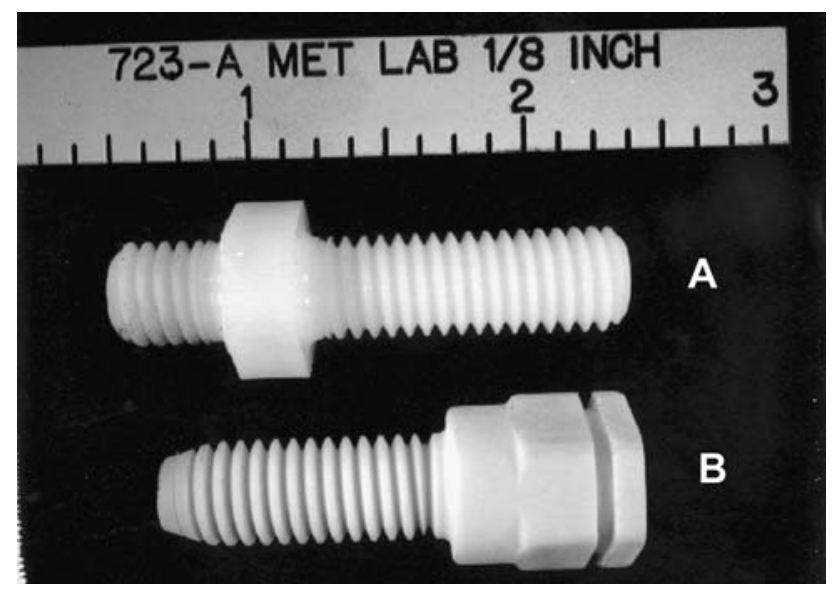

Fig. 15 Pressure relief nozzle types. Type A (new design) was used in an earlier vessel rupture. Type B (old design) was used in both ruptures described in this paper. Note the longer taper on Type B versus Type A

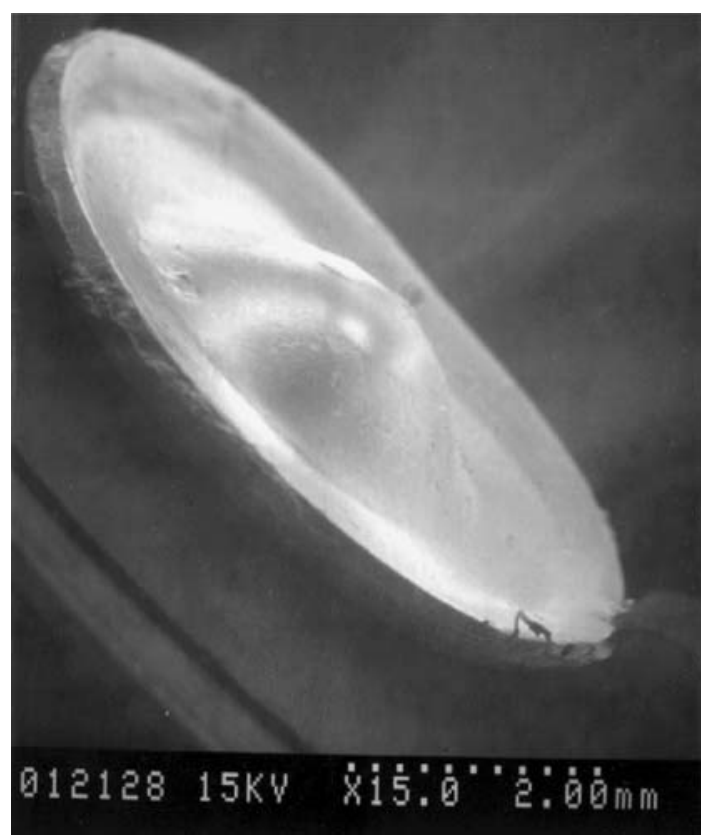

Fig. 16 Pressure relief disk from testing. The taper on the nozzle allowed disk deformation as pressure increased. Note the rolled-up edges. This disk does not rupture at normal operating pressures but distorts to allow air to escape around the nozzle threads

720 psig (5 MPa). Pressure testing was performed to determine release pressures of samples from our inventory. The pressure relief device includes a threaded nozzle (Fig. 15) allowing it to be hand threaded into the cap on the inner vessel and a rupture disk. The rupture disk, a solid, circular disk (Fig. 16) made of Teflon PFA (polyperfluoroalkoxyethylene), is inserted in the cap prior to threading the nozzle. The disk is approximately $0.020 \mathrm{in}$. $(0.5 \mathrm{~mm})$ thick with a $0.315 \mathrm{in} .(8 \mathrm{~mm})$ diameter and is

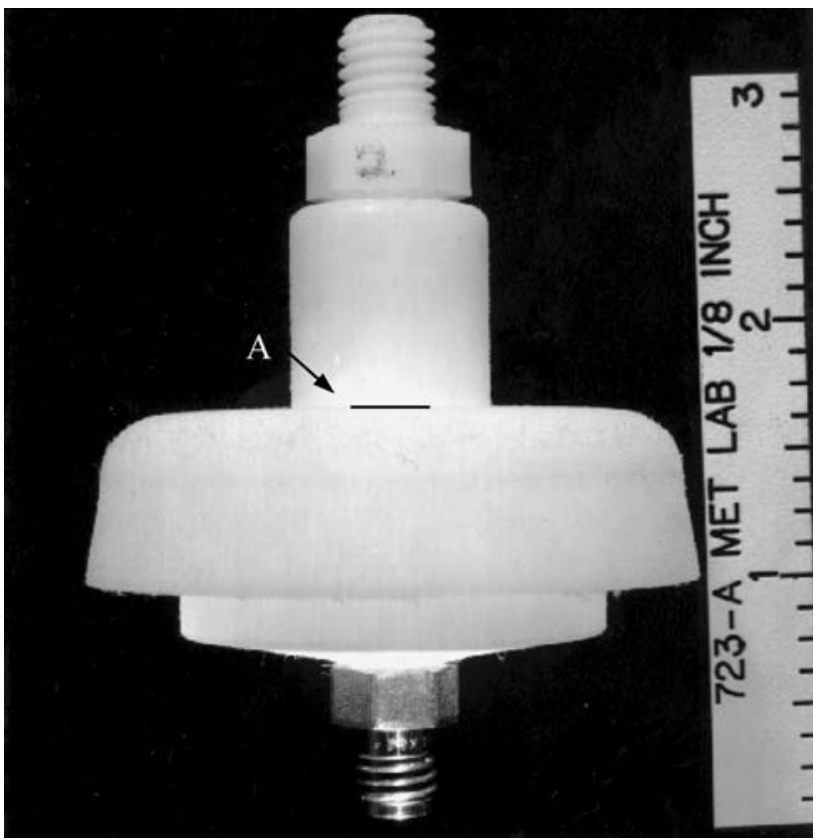

Fig. 17 PTFE inner vessel cap with pressure fitting attached for testing rupture disk rupture. Heating tape was wrapped around the outer diameter to increase temperature. The pressure relief disk is inserted at position $\mathrm{A}$, beneath nozzle

designed to deform around the circumference to allow pressure release through the threads.

The inner vessel cap was drilled and threaded to allow for hose attachment to a high-pressure fitting (Fig. 17). Early testing with a used nozzle and new rupture disk resulted in measured release pressures of 1025-1267 psig (7-8.7 MPa). This testing was accomplished using a pressure rise rate of $120 \mathrm{psig} / \mathrm{min}(0.8 \mathrm{MPa} / \mathrm{min})$. Heater tape was wrapped around the cap for testing at higher temperatures, $98-104{ }^{\circ} \mathrm{C}$. At the elevated temperature the release pressure was measured at 785-968 psig (5.4-6.7 $\mathrm{MPa})$. These elevated temperature tests were conducted using a new nozzle of the old design and a lower pressure rise rate. Pressure release in all tests was very audible and gage pressure dropped significantly. It was also observed that the used nozzle was easy to hand thread whereas the new nozzle was more difficult. After the initial test with the new nozzle, the ease of threading was similar to that for used nozzle. Pressurization of the new threads probably caused thread deformation to allow easier fit-up during the next use.

Doubling the pressure rise to $240 \mathrm{psig} / \mathrm{min}(1.7 \mathrm{MPa} / \mathrm{min})$ resulted in release pressures of 1398-1428 psig (9.6$9.9 \mathrm{MPa}$ ) with a used and a new nozzle (old design). Since these pressures were very high, a pressure rise of $120 \mathrm{psig} /$ min was used for remaining tests. A new nozzle design (Fig. 18) with a flat face was also tested. At room temperature, the release pressures were 832-848 psig (5.7-5.9 MPa) 

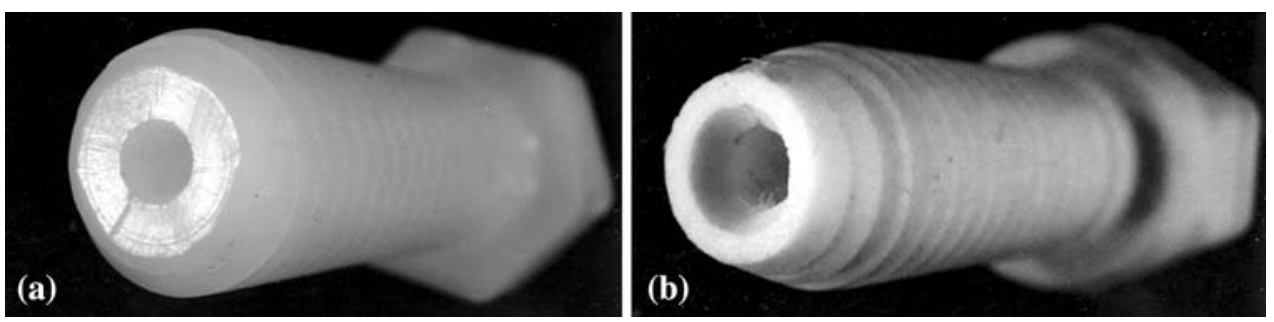

Fig. 18 Face of Type A pressure relief nozzle is flat with no ID taper. Face diameter is approximately 5/16 in. Hole diameter is approximately 0.075 in. Face of Type B pressure relief nozzle has a taper. Face diameter is approximately 5/16 in. Hole diameter (B) is approximately $0.080-$ $0.084 \mathrm{in.}$

with gage pressures dropping very slowly after the release. These pressure values were a little higher than with the old design nozzle. This is expected since the new nozzle design has a flat head versus the bevel design on the old nozzle. In all tests, the rupture disk did not fail but did provide a path for pressure release. However, the relief pressures were higher than the manufacturer's test results. These higher than anticipated release pressures are consistent with the bioassay vessels failures during service. Simply put, the pressure inside the inner vessel may not have been released by the rupture disk and the inner vessel pressure ultimately exceeded the pressure required to induce rupture in the outer vessel.

\section{Calculations}

The physical evidence demonstrates that failures initiated in the outer vessels when the mechanically induced stresses exceeded the strength of the vessel wall. The wall stresses were induced because of tightening the outer vessel cap to seal the inner vessel and the expansion of the inner vessel as it was heated and pressurized. Improper installation of the thermal shield contributed significantly to the first failure while localized bulging of the inner vessel caused the initiation of the second failure. However, both the second failure and the original failure that was not a part of this analysis demonstrated that when the inner vessel failed, the pressure that developed in the outer vessel was sufficient to rupture the outer vessel. Therefore, pressure vessel calculations were performed on the outer vessel using hoop stresses per Roark and Young [4] with guidance from ASME Section VIII [5]. Note: ASME Section VIII was written for the use of metallic materials only; thus, calculations using the ASME Section VIII are for comparison purposes only.

The maximum calculated circumferential stress is 2731 psi $(18.8 \mathrm{MPa})$ when the internal pressure in the vessel is 550 psi (3.8 MPa). With internal pressures of 600 and 800 psig (4.1 and 5.5 MPa), the calculated circumferential stress is 2980 and 3973 psi (20.6 and 27.4 MPa), respectively [4].
Table 1 Mechanical properties of vessel materials

\begin{tabular}{|c|c|c|}
\hline & $\begin{array}{c}\text { PEI outer vessel } \\
\text { (30\% glass reinforced) }\end{array}$ & $\begin{array}{c}\text { PTFE } \\
\text { inner vessel }\end{array}$ \\
\hline \multicolumn{3}{|c|}{ Ultimate tensile strength, psi (MPa) } \\
\hline $23^{\circ} \mathrm{C}\left(73^{\circ} \mathrm{F}\right)$ & $23300(161)$ & $5800(40)$ \\
\hline $150{ }^{\circ} \mathrm{C}\left(302^{\circ} \mathrm{F}\right)$ & $14225(98)$ & \\
\hline $177^{\circ} \mathrm{C}\left(351^{\circ} \mathrm{F}\right)$ & $12000(83)$ & \\
\hline $190^{\circ} \mathrm{C}\left(374^{\circ} \mathrm{F}\right)$ & $8000(55)$ & \\
\hline $204^{\circ} \mathrm{C}\left(400{ }^{\circ} \mathrm{F}\right)$ & & $1247(8.6)$ \\
\hline $220^{\circ} \mathrm{C}\left(446^{\circ} \mathrm{F}\right)$ & $8190^{\mathrm{a}}(56.5)$ & $1000^{\mathrm{a}}(7)$ \\
\hline \multicolumn{3}{|c|}{ Allowable strength, psi (manufacturer's data) } \\
\hline$-20^{\circ} \mathrm{C}\left(-4^{\circ} \mathrm{F}\right)$ & $8000(55)$ & \\
\hline $0{ }^{\circ} \mathrm{C}\left(32^{\circ} \mathrm{F}\right)$ & $7100(49)$ & \\
\hline $23^{\circ} \mathrm{C}\left(73^{\circ} \mathrm{F}\right)$ & $6200(42.8)$ & \\
\hline $93{ }^{\circ} \mathrm{C}\left(199^{\circ} \mathrm{F}\right)$ & $4600(31.7)$ & \\
\hline $177^{\circ} \mathrm{C}\left(351^{\circ} \mathrm{F}\right)$ & $2900(20)$ & \\
\hline \multicolumn{3}{|l|}{ Elongation, \% } \\
\hline $23^{\circ} \mathrm{C}\left(73^{\circ} \mathrm{F}\right)$ & 3 & 650 \\
\hline $150{ }^{\circ} \mathrm{C}\left(302^{\circ} \mathrm{F}\right)$ & 1.55 & NA \\
\hline \multicolumn{3}{|c|}{ Continuous use temperature } \\
\hline${ }^{\circ} \mathrm{C}\left({ }^{\circ} \mathrm{F}\right)$ & $180(356)$ & $260(500)$ \\
\hline
\end{tabular}

${ }^{a}$ Linear regression values from tensile stress versus temperature data

The allowable stress level at $177{ }^{\circ} \mathrm{C}$ as per Table 1 is above the calculated stress value at 550 psi but below the calculated stress values when the pressure reaches 600 psi. Thus, the actual pressure that must have developed in the outer vessel upon rupture (or venting) of the inner vessel must have been at least 600 psig per the Roark and Young calculation. The ASME calculation results in an allowable stress of $2976 \mathrm{psi}(20.5 \mathrm{MPa})$ when the internal pressure is 700 psig. The ASME allowable pressure estimate thus is similar to the Roark and Young calculation. Taken together, these calculations suggest that the pressures developed in the outer vessel were probably within the range of $600-800$ psig (4.1-5.5 MPa) at vessel rupture.

Development of a $600-800 \mathrm{psig}(4.1-5.5 \mathrm{MPa})$ pressure in outer vessel requires that the inner vessel pressure 
exceed those values. Additionally, it should be emphasized that the inner vessel probably did not vent until failure initiated in the outer vessel. Therefore, for the outer vessel to shatter, as observed in the second failure, the pressure release from the inner vessel had to greatly exceed the ability of the outer vessel to vent.

Development of excessive pressures in the inner vessel depends on several factors:

1. The pressure relief device must fail to vent at its design pressure. The vent pressure is a function of temperature, rate of pressure rise and disk placement. The lack of venting at inner vessel pressures in excess of 700 psig has been clearly demonstrated; thus this factor can easily be satisfied.

2. The bioassay sample in the vessel of interest must behave differently (induce higher pressures) than the sample in the control vessel. There are ten samples in a batch and only one sample is attached to the control system. Each sample is different; thus this factor is also easily satisfied.

3. The combination of stresses induced on the outer vessel by the processes of cap tightening, thermal expansion, internal pressurization and localized deformation of the inner vessel must exceed the mechanical strength of the outer vessel. The fact that very few failures have occurred demonstrates that this factor is seldom satisfied.

\section{Material Properties}

A form of PTFE is used for inner vessel construction (Fig. 5) primarily for its superior chemical inertness. The actual material is DTFM, a modification of PTFE. The mechanical properties of DTFM (Table 1) show that tensile strength is approximately $5800 \mathrm{psi}(40 \mathrm{MPa})$ and the elongation is $650 \%$ at room temperature [1]. At 204 and $260{ }^{\circ} \mathrm{C}$, the tensile strength drops significantly to 1250 and 870 psi ( 8.6 and $6 \mathrm{MPa}$ ), respectively. The $870 \mathrm{psi}$ value is based on PTFE data which may be slightly higher than that for the DTFM. Elongation values above room temperature are not available but are assumed to be higher than those at room temperatures. While there is no definitive glass transition temperature for PTFE, the softening temperature is $260{ }^{\circ} \mathrm{C}$ which is also the continuous use temperature for this version of PTFE. This is above the standard bioassay test temperature of $220{ }^{\circ} \mathrm{C}$.

The outer vessel and the thermal shield are injection molded with a PEI thermoplastic filled with $30 \%$ glass fiber [1]. The tensile strength of this polymer is approximately 4 times higher than the PTFE strength (Table 1) and about 8 times the strength at $150{ }^{\circ} \mathrm{C}$. The PEI strength shows an approximately $50 \%$ reduction between 150 and $220{ }^{\circ} \mathrm{C}$. Although strength is much higher than PTFE, the PEI resin is limited in ductility and toughness. At room temperature, the elongation value is only $3 \%$ [1] and is estimated to be $1.55 \%$ at $150{ }^{\circ} \mathrm{C}$. The manufacturer's product guide states that the PEI resin is suitable for continuous service at temperatures up to $180{ }^{\circ} \mathrm{C}$ [1] or $40^{\circ} \mathrm{C}$ below the inner vessel operating temperature. Additionally, a potential fatigue problem also exists with long-term use of this PEI polymer at high temperatures. The glass transition temperature, $T_{\mathrm{g}}$, for the PEI material is $215^{\circ} \mathrm{C}\left(419^{\circ} \mathrm{F}\right)$ which means that increased molecular mobility above this temperature may cause significant changes in material properties [1].

Data for the PEI resin show a significant reduction in impact strength after $40 \mathrm{~h}$ of steam sterilization cycles (30 $\mathrm{min} / \mathrm{cycle}$ ) at $132{ }^{\circ} \mathrm{C}$ per ASTM D1822 [6]. The effect of dry sterilization at $160{ }^{\circ} \mathrm{C}$ (time not specified) shows no effects on this particular PEI polymer [7]. Therefore, the presence of moisture appears to have significant impact upon temperature stability. In addition, multiple temperature cycles above these temperatures may increase degradation.

The mechanical property data suggest that the load carrying capacity of the outer vessel decreases with use. This decrease represents another factor that can contribute to the potential for failure. The number of cycles that can be accommodated without compromising the properties of the material has not been established. Therefore, testing should be performed to identify this cycle limit.

\section{Conclusion and Recommendations}

Two bioassay vessels failed during testing in the SRS bioassay laboratory facilities. The first vessel rupture is attributed to incorrect placement of the thermal shield disk. A bright color stripe is suggested for use at the top of the inner vessel to allow quick identification of improper placement of the thermal shield. The second vessel rupture is attributed to over pressurization based on calculations and non-release of the pressure relief device. No flaws were found in this vessel that would impair structural integrity.

A digital display of the temperature and pressure may be necessary to allow the operator to respond to faulty sensors. The use of thicker, cylindrical vessels or fiber-reinforcement type webbing wrapped around the outer vessel would provide additional pressure protection. If possible, content weight could be reduced to allow lower operating pressures. Since moisture can cause pressure in the annular space, the vessels need to be as dry as possible to minimize pressure buildup. Since thermal aging of the vessels may be detrimental to their performance, it is recommended that additional tests be performed in order to determine cycle 
life. Testing is also recommended to verify uniform heating and pressure generation at maximum temperatures for all vessel locations.

However, it should be recognized that failure is a very infrequent event and that the consequences of any failure can be minimized by reducing the maximum pressure allowed to develop in the inner vessel. Therefore, at a minimum, the pressure release device should be modified to assure vessel venting at the desired maximum pressure.

Acknowledgments The author acknowledges the following SRNL personnel for their assistance in this work: Tony Curtis, Bridget Miller, James Piercy, and Carla Loftin.

\section{References}

1. Materials Reference. http://www.matweb.com

2. GE Engineering Thermoplastics Product Guide, Ultem PEI Resin, October 1997

3. Engineered Materials Handbook, Engineering Plastics, vol. 2, pp. 16-21. ASM International (1988)

4. Roark, R.J., Young, W.C.: Formulas for Stress and Strain, 5th edn., p. 504. McGraw-Hill, New York (1975)

5. ASME Boiler and Pressure Vessel Code, Section VIII-Division I, Pressure Vessels, Section UG-27 (1992), p. 24

6. Plastics Design Library, The Effect of Sterilization Methods on Plastics and Elastomers, p. 171. William Andrew (1994)

7. Plastics Design Library, The Effect of Sterilization Methods on Plastics and Elastomers, p. 161. William Andrew (1994) 